\title{
What are Belief Systems?
}

\author{
J. L. Usó-Doménech · J. Nescolarde-Selva
}

Published online: 14 January 2015

C) Springer Science+Business Media Dordrecht 2015

\begin{abstract}
In beliefs we live, we move and we are [...] the beliefs constitute the base of our life, the land on which we live [...] All our conduct, including the intellectual life, depends on the system of our authentic beliefs. In them [...] lies latent, as implications of whatever specifically we do or we think [...] the man, at heart, is believing or, which is equal, the deepest stratum of our life, the spirit that maintains and carries all the others, is formed by beliefs...(Ortega y Gasset)
\end{abstract}

We know that the human being is a social animal. This is a common fact. Moreover, the human being is defined as a rational being. It is clear and nobody can deny that human creations include logic, mathematics, philosophy, science, and jurisprudence. These are all products of rationality or abstract thought. Nevertheless, human sociability goes further that the sociability of an animal herd. Societies were founded, cohere, develop, degenerate and die based on their belief systems. Reason cannot prove the beliefs it is based upon. Beliefs arise through experience. Experience needs previous beliefs and reason to be assimilated, and reason needs experience to be formed, as beliefs need reason as well. Beliefs, reason and experience, are based upon each other. Context is dynamic, and formed upon beliefs, reason and experience. This is where relative understanding lies. As relative understanding is independent of our context, it is also dependant on our beliefs, reasoning, and experiences. Contexts are dynamic because they are changing constantly as we have new experiences and change our beliefs and our ways of reasoning.

The use of the term "belief system" can be highly confusing. Psychologists, political scientists and anthropologists tend to use the term in rather different senses. There is some network of interrelated concepts and propositions at varying levels of generality, and there are some processes by which a human or a computer accesses and manipulates that knowledge under current activating circumstances and/or in the service of particular current purposes. Belief systems are structures of norms that are interrelated and that vary mainly in the degree in which they are systemic. What is systemic in the Belief system is the interrelation between

J. L. Usó-Doménech · J. Nescolarde-Selva ( $\bowtie)$

Department of Applied Mathematics, University of Alicante, Alicante, Spain

e-mail: josue.selva@ua.es 
several beliefs. What features warrant calling this stored body of concepts a belief system? Belief systems are the stories we tell ourselves to define our personal sense of Reality. Every human being has a belief system that they utilize, and it is through this mechanism that we individually, "make sense" of the world around us. Perceived Reality is constructed by means of systems of signs, being affected and being changed by means of Belief systems. A subject cannot understand a sign without talking about a system that is learned socially and that allows him to make sense of perception. In the same way, the classification of signs in closed typologies can be deceptive, since the status of the sign depends strongly on the form in which the sign is used within the Belief system. A signifier can nevertheless be iconic in a belief context and be symbolic in another context. From this we can see that people are capable of constructing all manner of individual beliefs by which they tell stories about how the world works. As humans, we tend to use all these belief systems in varying degrees to cope with events in our lives. Ultimately we need the world to make sense . Therefore, those areas where that "sense of reality" is most challenged will tend to be the areas in which the most controversies exist.

Moreover, these signs are not rational. The species Homo sapiens developed so-called belief systems. These sets of beliefs are reinforced by culture, theology, and experience and training as to how society works cultural values, stereotypes, political viewpoints, etc. Beliefs are often considered as convictions or as religious beliefs, but as scientists there are also philosophical beliefs relating to the sphere of daily life. If a stimulus is received, it may be interpreted through the belief system to be whatever the belief system might lead the recipient to rationalize. A belief system need have no basis in reality so long as it consistently provides adequate explanations. It takes us to define a human being like Homo religious.

\section{Characteristics of Belief Systems}

Belief systems have the following properties, and through them social significance. Some characteristics of belief systems are:

(1) Personal commitment is one of most observable and interesting features of an ideology. If it were not for the fact of personal commitment, belief systems could not have strong social consequences, and the study of social systems would not be so interesting.

(2) Belief systems have an existence that is independent of their committed believers. The believers do not wholly contain the belief system; in fact, they are unlikely to be aware of more than a small part of it and, knowingly or unknowingly, they must take the rest of the belief system on faith.

(3) Psychological mechanisms such as cognitive congruence may help explain individual commitment, but they do not necessarily explain the connectedness of a belief system in human society.

(4) The life span of a belief system is potentially longer than the life span of believers.

(5) Belief systems vary almost infinitely in substantive content.

(6) The boundaries of a belief system are generally, although not always, undefined. Collections of beliefs do not generally have neat boundaries.

(7) The elements (concepts, propositions, rules, etc.) of belief systems are not consensual. That is, the elements of one system might be quite different from those of a second in the same content domain. And a third system may be different from each. Individual differences of this kind do not generally characterize ordinary knowledge systems, except insofar as one might want to represent differences in capability or complexity. 
Belief systems may also vary in complexity, but the most distinctive variation is conceptual variation at a roughly comparable level of complexity. An interesting sidelight on the consensuality question is whether a belief system is "aware," in some sense, that alternative constructions are possible. For cognitive science, the point of this discussion is that nonconsensuality should somehow be exploited if belief systems are to be interesting in their own right as opposed to knowledge systems. Belief systems often appear to have clear boundaries when the separation is really between social groups.

(8) Belief systems are in part concerned with the existence or nonexistence of certain conceptual entities. God, motherland, witches, and assassination conspiracies are examples of such entities. This feature of belief systems is essentially a special case of the nonconsensuality feature. To insist that some entity exists implies an awareness of others who believe it does not exist. Moreover, these entities are usually central organizing categories in the belief system, and as such, they may play an unusual role which is not typically to be found in the concepts of straightforward knowledge systems.

(9) Belief systems often include representations of alternative worlds, typically the world as it is and the world as it should be. Revolutionary or Utopian belief systems especially have this character. The world must be changed in order to achieve an idealized state, and discussions of such change must elaborate how present reality operates deficiently, and what political, economic, social (etc.) factors must be manipulated in order to eliminate the deficiencies.

(10) Belief systems rely heavily on evaluative and affective components. There are two aspects-to this, one 'cognitive'; "the other "motivational." Belief systems typically has large categories of concepts defined in one way or another as themselves "good" or "bad," or as leading to good or bad outcomes. These polarities, which exert a strong organizing influence on other concepts within the system, may have a very dense network of connections rare in ordinary knowledge systems. From a formal point of view, however, the concepts of "good" and "bad" might for all intents and purposes be treated as cold cognitive categories just like any other categories of a knowledge system.

(11) Belief systems are likely to include a substantial amount of episodic material from either personal experience or (for cultural belief systems) from folklore or (for political doctrines) from propaganda.

(12) The content set to be included in a belief system is usually highly "open." That is, it is unclear where to draw a boundary around the belief system, excluding as irrelevant concepts lying outside. This is especially true if personal episodic material is important in the system. Consider, for example, a parental belief system about the irresponsibility and ingratitude of the modem generation of youth. Suppose, as might very well be the case, that central to this system is a series of hurtful episodes involving the believer's own children. For these episodes to be intelligible, it would be necessary for the system to contain information about these particular children, about their habits, their development, their friends, where the family lived at the time, and so on. And one would have to have similar conceptual amplification about the "self" of the believer.

(13) Beliefs can be held with varying degrees of certitude. The believer can be passionately committed to a point of view, or at the other extreme could regard a state of affairs as more probable than not. This dimension of variation is absent from knowledge systems. One would not say that one knew a fact strongly. There exist some examples of attempts to model variable credences or " "confidence weights" of beliefs and how these change as a function of new information. A distinction should be made between the certitude attaching to a single belief and the strength of attachment to a large system of beliefs. 


\section{Elements of Belief Systems}

The following elements are listed in the order that would be logically required for the understanding a belief system. This does not imply priority in value or in a causal or historical sense.

(1) Values Implicitly or explicitly, belief systems define what is good or valuable. Ideal values tend to be abstract summaries of the behavioral attributes which social system rewards, formulated after the fact. Social groups think of themselves, however, as setting out various things in order to implement their values. Values are perceived as a priori, when they are in fact a posteriori to action. Having abstracted an ideal value from social experience, a social group may then reverse the process by deriving a new course of action from the principle. At the collective level of social structure, this is analogous to the capacity for abstract thought in individual subjects and allows great (or not) flexibility in adapting to events. Concrete belief systems often substitute observable social events for the immeasurable abstract ideal values to give the values immediate social utility.

(2) Substantive beliefs ( $\mathrm{Sb}$ ) They are the more important and basic beliefs of a belief system. Statements such as: all the power for the people, God exists, Black is Beautiful, and so on, comprise the actual content of the belief systems and may take almost any form. For the believers, substantive beliefs are the focus of interest.

(3) Orientation The believer may assume the existence of a framework of assumptions around his thought, it may not actually exist. The orientation he shares with other believers may be illusory. For example, consider almost any politic and sociologic belief system. Such a system evolves highly detailed and highly systematic doctrines long after they come into existence and they came into existence for rather specific substantive beliefs. Believers interact, share specific consensuses, and give themselves a specific name: Marxism, socialism, Nazism, etc. Then, professionals of this belief system work out an orientation, logic, sets of criteria of validity, and so forth.

(4) Language It is the logic of a belief system. Language $\mathbf{L}$ of a belief system is composed of the logical rules which relate one substantive ${ }^{1}$ belief to another within the belief system. Language must be inferred from regularities in the way a set of substantive beliefs is used. The language will be implicit, and it may not be consistently applied. Let Sb be a substantive belief. We propose the following rules of generation of belief systems:

$$
\begin{aligned}
& R 1 \rightarrow \text { Pred } \rightarrow \text { substantive beliefs } \rightarrow \bigcup_{k=1}^{n} S b_{k}=S b_{j} \\
& R 2 \rightarrow \text { Arg } \rightarrow \text { hypothesis }+ \text { goal } \rightarrow \text { why and what for } ? \\
& R 3 \rightarrow T \rightarrow \text { Pred } \wedge \text { Arg } \\
& R 4 \rightarrow T \rightarrow T[(\&)]^{n}, n \geq \varnothing \\
& R 5 \rightarrow \&=\left\{\begin{array}{l}
\wedge \\
\vee \\
\equiv
\end{array}\right.
\end{aligned}
$$

An argument is formed by the sum of two characteristics: (a) hypothesis, that is to say, so what is this physical and social reality? And (b) goal: we want this society to reach its "perfection" (utopia).

1 Substantive beliefs constitute the axioms of the system, while many derived beliefs will constitute their theorems. 
(5) Perspective The perspective of a belief system or their cognitive map is the set of conceptual tools. Central in most perspectives is some statement of where the belief system and/or social group that carries it stands in relation to other things, specially nature, social events or other social groups. Are we equals? Enemies? Rulers? Friends? Perspective as description of the social environment is a description of the social group itself, and the place of each individual in it. The perspective may be stated as a myth. It explains not only who subjects are and how subjects came to be in cognitive terms, but also why subjects exist in terms of ideal values. Meaning and identification are provided along with cognitive orientation.

(6) Prescriptions and proscriptions This includes action alternatives or policy recommendations as well as deontical norms for behavior. Historical examples of prescriptions are the Marx's Communist Manifesto, the Lenin's What is To Be Done or the Hitler's Mein Kampf. Deontical norms represent the cleanest connection between the abstract ideas and the concrete applied beliefs because they refer to behavior that is observable. They are the most responsive conditions in being directly carried by the social group through the mechanisms of social reward and punishment.

(7) Ideological Technology Every belief system contains associated beliefs concerning means to attain ideal values. Some such associated beliefs concern the subjective legitimacy or appropriateness of d-significances, ${ }^{2}$ while others concern only the effectiveness of various d-significances. For example, political activists and organizational strategy and tactics are properly called the technology of the belief system. Ideological Technology is composed of the associated beliefs and material tools providing means for the immediate or distant (Utopian) goals of a belief system. Ideological Technology is not used to justify or validate other elements of a belief system, although the existence of ideological technologies may limit alternatives among substantive beliefs. Ideological Technology commands less commitment from believers than do the other elements. A change in Ideological Technology (strategy) may be responsible for changes in logical prior elements of a belief system. Ideological Technology, like belonging to the Structural Base (Nescolarde-Selva and Usó-Doménech 2013a, b; Usó-Doménech and NescolardeSelva 2012) and having a series of prescriptions concerning doing can influence the life conditions of believers, thus forcing an adaptation in the belief system itself. Eurocommunism in Western Europe gives to a good historical example. Ideological Technology may become symbolic and it can cause more fundamental differences between belief systems and, therefore, be a source of conflict. Conflicts between anarchists and Communists in the Spanish Civil War or the ideas of Trotsky and those of Stalin in the USSR are examples. Much blood has been shed between Muslims and Hindus over the fact that their religions have different dietary restrictions (deontical prohibitions).

\section{Conclusions}

Conflict between two groups, including war, may be defined as a battle between belief systems. Symbols emerge strongly in such conflicts: they may be revered objects like stones, writings, buildings, flags or badges; whatever they may be, they may symbolize the central core of belief system. When people become symbols, the real person may become obscured behind the projected symbolic image or person. Organizations develop their own in-house culture and

2 The denotative systemic significance (d-significances) is the significance of the absolute beings. The concept of denotative systemic significance coincides with the concept of relative beings. 
belief system, too, which leads them to act and behave in ways that might not seem entirely rational to an outsider. Then: (a) Conflicts are not over Ideological Technology but over what symbolizes technological difference. (b) Substantive beliefs are understood only in terms of ideal values, criteria of validity, language and perspective. (c) A Believer is usually better able to verbalize substantive beliefs than values, criteria, logical principles or orientation, which is apt to be the unquestioned basis from which he proceeds. (d) Ideal values, criteria of validity, language and perspective may have been built up around a substantive belief to give it significance and justification.

\section{References}

Nescolarde-Selva, J., \& Usó-Doménech, J. L. (2013a). Topological structures of complex belief systems. Complexity, 19, 46-62. doi:10.1002/cplx.21455.

Nescolarde-Selva, J., \& Usó-Doménech, J. L. (2013b). Topological structures of complex belief systems (II): Textual materialization. Complexity, 19, 50-62. doi:10.1002/cplx.21476.

Usó-Doménech, J. L., \& Nescolarde-Selva, J. (2012). Mathematic and semiotic theory of ideological systems. Editorial LAP. Germany: Sarrebruck.

J. L. Usó-Doménech graduated in Sciences in 1968 and Doctor in Mathematics by the University of Valencia (Spain) in 1991. Since 1991, he has been working in the Department Mathematics, University of Castellon, Spain. He is currently retired. He made his doctoral thesis on a mathematical model of a terrestrial mediterranean ecosystem. He has directed many doctoral thesis in Theory of Systems. He is author and coauthor of several papers in journals, proceedings and books. He has obtained scholarships of research in many universities (University of Joensuu, Finland; University of Ben Gurion of Negev, Israel and the University of Georgia, USA). He has collaborated in numerous occasions with the Wessex Institute of Technology (UK) and fruit of this collaboration was the creation of the international congress ECOSUD.

J. Nescolarde-Selva graduated in Mathematics from the University of Havana (Cuba) in 1999. He won the award: Gold Title at the University of Havana, Cuba in 1999. He received the PhD degree in Mathematics from the University of Alicante (Spain) in 2010. Since 2002, he has been working in the Department of Applied Mathematics, University of Alicante, Spain. He is author and co-author of several papers in journals, and books. He is devoted to research on the Theory of Systems. 